\title{
Marine reserve designation, trophic cascades and altered community dynamics
}

\author{
David O'Sullivan ${ }^{1}$, Mark Emmerson ${ }^{1,2,3, *}$ \\ ${ }^{1}$ School of Biological, Earth and Environmental Sciences, University College Cork, The Cooperage, Distillery Fields, \\ North Mall, Cork, Ireland \\ ${ }^{2}$ Environmental Research Institute, University College Cork, Lee Road, Cork, Ireland \\ ${ }^{3}$ School of Biological Sciences, Medical and Biological Centre, Queen's University Belfast, 97 Lisburn Road, Belfast BT9 7BL, \\ Northern Ireland, UK
}

\begin{abstract}
Marine ecosystems and their associated populations are increasingly at risk from the cumulative impacts of many anthropogenic threats that increase the likelihood of species extinction and altered community dynamics. In response, marine reserves can be used to protect exploited species and conserve biodiversity. The increased abundance of predatory species in marine reserves may cause indirect effects along chains of multi-trophic interactions. These trophic cascades can arise through direct predation, density-mediated indirect interactions (DMIIs), or indirect behavioural effects, termed trait-mediated indirect interactions (TMIIs). The extent of algal cover and the abundance of 4 primary consumers were determined in Lough Hyne, which was designated Europe's first marine nature reserve in 1981. The primary consumers were the sea urchin Paracentrotus lividus, the topshell Gibbula cineraria, the oyster Anomia ephippium, and the scallop Chlamys varia. The abundances of 3 starfish species (Marthasterias glacialis, Asterias rubens, and Asterina gibbosa) were also determined, as were 2 potential crustacean predators, Necora puber and Carcinus maenas. These data were compared with historical data from a 1962 (prey) and a 1963 (predator) survey to determine the nature of community interactions over adjacent trophic levels. The present study reveals a breakdown in population structure of the 4 surveyed prey species. Marine reserve designation has led to an increase in predatory crabs and M. glacialis, a subsequent decrease in primary consumers, especially the herbivore P. lividus, and an increase in macroalgal cover which is indicative of a trophic cascade. The study shows that establishing a Marine Reserve does not guarantee that conservation benefits will be distributed equally.
\end{abstract}

KEY WORDS: Trophic cascades - Trait mediated indirect interactions - Marine reserves · Paracentrotus lividus

\section{INTRODUCTION}

Marine ecosystems and their associated populations continue to be at risk from irrevocable damage in the face of anthropogenic threats. Human-induced changes to biodiversity are directly mediated by exploitation, habitat destruction and pollution (Pauly et al. 1998), which can directly influence species dynamics and indirectly determine the structure of whole assemblages by altering food web structure (Micheli et al. 2004). There are inherent difficulties in accurately quantifying marine populations, especially as historical baselines shift to produce the phenomena of 'sliding baselines' (Jackson 2001). In the face of such changes, and given the need to put in place measures to conserve natural populations sub- 
ject to exploitation, there is a real danger of overestimating threats and sensationalizing the process of extinction.

Studies of marine reserves allow large-scale manipulations of human activities and represent an opportunity to test for cascading effects of predator removal or addition at meaningful spatial and temporal scales (Guidetti 2006). In simple terms, a top predator can control herbivore or prey density by consumption and, in doing so, indirectly affect the abundance of primary producers. Trophic cascades are generally characterised by top-down control of assemblage structure by predators, conspicuous indirect effects, and a persistence of alternative community states (Shears \& Babcock 2003). Density-mediated indirect interactions (DMIIs) occur when changes in the abundance of one species affect the density of another species through direct predation, which will in turn change the density of a third species (Heithaus et al. 2008).

Predators can also alter prey traits with non-lethal effects; the resulting changes in prey behaviour due to the presence of a predator are known as risk effects. These behavioural changes involve a tradeoff between optimal foraging and predator avoidance, which leads to reduced foraging time and the increased possibility of starvation (Nelson et al. 2004) and results in altered prey behaviour or morphology, with subsequent impacts on competitive interactions and community structure. These indirect interactions are termed trait-mediated indirect interactions (TMIIs) (Werner \& Peacor 2003). Therefore, predation strongly influences prey fitness and subsequent dynamics, even in the absence of direct killing, and the numerical response of producers and herbivores to predator abundance is the sum of density and trait mediated effects (Heithaus et al. 2008).

Designation of marine reserves and comparisons between no-take reserves and adjacent fishing areas have shown that protection can lead to greater abundances, biomasses, sizes, and diversity in coastal marine assemblages (e.g. Willis et al. 2003). While these studies demonstrate that reserves are a powerful management and conservation tool with many benefits, there may be unforeseen consequences of marine reserve designation. It is suggested that marine reserves may act as an indirect control on biodiversity through influences on species abundance (Lindberg et al. 1998). In the present study, the consequences of marine reserve designation in Europe's oldest marine reserve, Lough Hyne, southwest Ireland, are explored.

Lough Hyne, designated as a marine reserve in 1981, is a semi-enclosed sea lough separated from the Northeast Atlantic by a narrow channel called the Rapids. Since designation, populations of a number of subtidal benthic invertebrates have undergone catastrophic declines in the system, without recovery. For example, the best-studied invertebrate in Lough Hyne, the purple sea urchin Paracentrotus lividus, was found to be absent from the South Basin by 2000 (Barnes et al. 2001). The purple sea urchin is the subject of a long-term population study due to its importance as a primary grazer and role in regulating algal biomass, and the population is observed to fluctuate periodically. After a brief recovery period in the early 1980s, the population declined by as much as 12 population halvings (Uthicke et al. 2009). Although $P$. lividus is not demonstrated to be a keystone species at Lough Hyne (Kitching 1987), it undoubtedly has a stabilising influence in the system and its loss has community level implications. Previous studies explored the drivers of population change and invoked mechanisms such as recruitment driven by sea surface temperature (Barnes et al. 2001) and intrinsic population dynamical processes (Uthicke et al. 2009).

The overarching aim of the present study was to explore the efficacy of marine reserve designation in conserving biological diversity by investigating the mechanisms underlying the reported declines of benthic invertebrates occupying adjacent trophic levels within Lough Hyne marine reserve. A survey was conducted to quantify the abundance and distribution of 4 common primary consumers, i.e. Paracentrotus lividus, Gibbula cineraria, Anomia ephippium and Chlamys varia. The abundances of the predatory starfishes Marthasterias glacialis and Asterias rubens, the detritivore Asterina gibbosa, and 2 predatory crab species, Necora puber and Carcinus maenas, were determined. The data were compared to records from a 1962 (prey) and 1963 (predator) survey by Muntz et al. (1965), enabling an assessment of population change since that survey. $N$. puber and $C$. maenas are capable of preying on any of the aforementioned species provided the prey are of manageable size. Similarly, both M. glacialis and A. rubens eat small primary consumers, thus establishing trophic interactions within the subtidal zone (Muntz et al. 1965, Thrush 1988). A 1979 algal survey (Kitching \& Thain 1983) provides data on algal coverage in Lough Hyne immediately prior to reserve designation. Comparable data from the present study allowed a more thorough investigation into whether primary productivity (bottom-up) or predation pressure (top-down) determines population size of the 4 primary consumers within the system since its desig- 
nation as a marine reserve. In this context, we tested 4 hypotheses: (1) that $P$. lividus has become extinct at Lough Hyne; (2) that predation has caused the decline of $P$. lividus; (3) the decline of $P$. lividus has impacted ecosystem processes, such as primary productivity; and (4) that similar declines are observable in other taxa, reflecting an ecosystem-wide reorganisation of the benthic community.

\section{MATERIALS AND METHODS}

\section{Study area}

The study was conducted at Lough Hyne marine reserve on the southwest coast of Ireland between 31 May and 11 August 2010 and replicated a 1962 (prey) and 1963 (crab) survey by Muntz et al. (1965). The site is diverse with respect to habitats and is an ideal place to study the effects of differing ecological processes on populations. Seven sites, as per Muntz et al. (1965), were surveyed for potential crustacean prey species (see Fig. 1-black circles). The sites exist in one of 2 distinct basins within Lough Hyne. North Basin sites are predominately shallow with less boulder scree and finer soft sediment. In the South Basin, sites are characterised by deep layers of large boulders. Sites were accessed and surveyed by boat. An additional 5 sites as described in Muntz et al. (1965) were also surveyed to facilitate a comprehensive survey of Paracentrotus lividus and crustacean predators at all sites in the South Basin. These sites were Mermaid Rock, Kitching Lab, Labhra Cliff, South West Bay South Island, and South Island (see Fig. 1-white circles). See also Table S1 in the supplement at www.int-res.com/ articles/suppl/m440p115_supp.pdf.

\section{Crab survey}

The distribution and abundance of epibenthic predators in the shallow intertidal zone was investigated with the use of lobster pots, following the Muntz et al. (1965) methodology. Four pots baited with fish heads and spaced $5 \mathrm{~m}$ apart, were laid overnight between the hours of dusk (19:00 to 21:00 h) and dawn (07:00 to 09:00 h), incorporating a full tidal cycle at each of the 12 sites described above. The aperture through which the crabs could enter the pots was $14 \mathrm{~cm}$ in diameter. In the morning, all specimens were brought back to the laboratory for identification and simple morphometric measurements (weight, carapace width) and returned to the respective site afterwards.

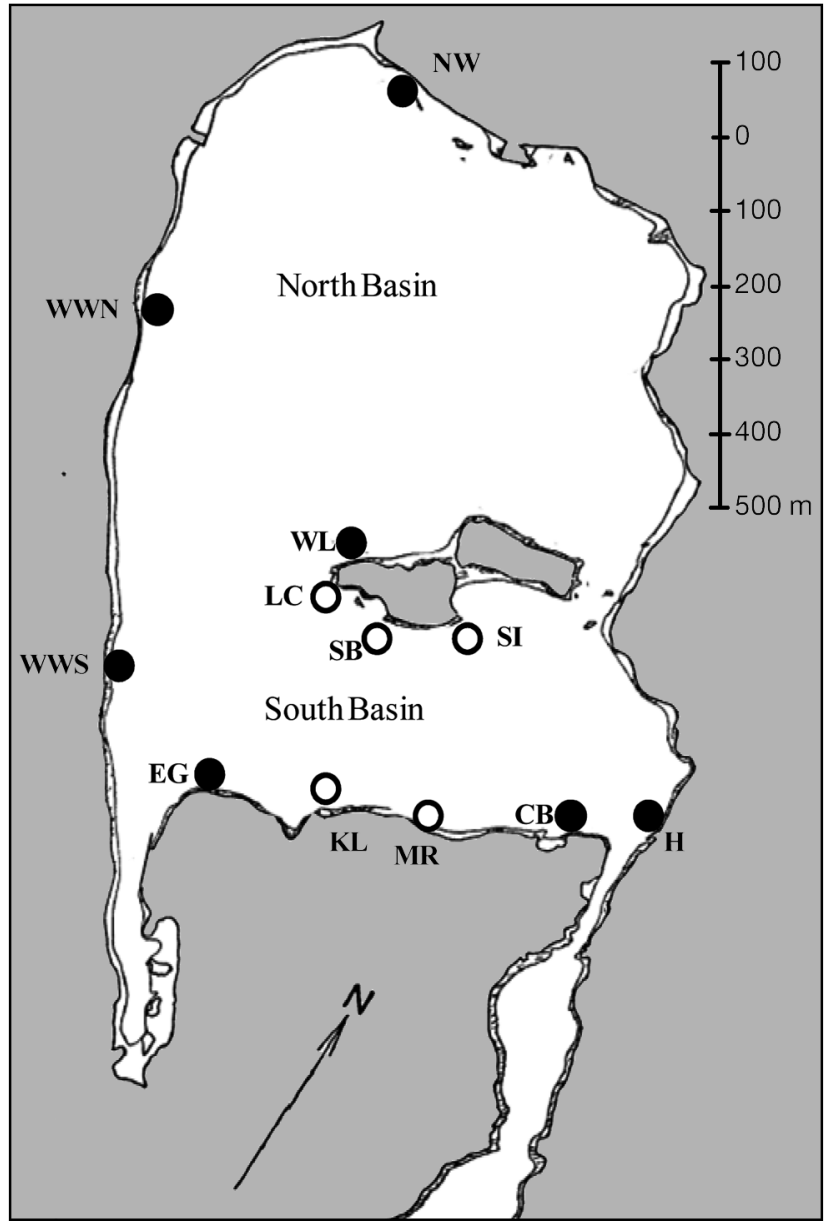

Fig. 1. Lough Hyne in southwest Ireland showing $(\bullet)$ the sites surveyed for the present study and in the original survey by Muntz et al. (1965). (O) Additional South Basin sites in the present study surveyed for Paracentrotus lividus and crustacean predators for comparison with Muntz et al. (1965). Site abbreviations are as follows - CB: Codium Bay, MR: Mermaid Rock, KL: Kitching Lab, EG: East Goleen, WWS: Westwood South, WWN: Westwood North, NW: North Wall, WL: West Labhra, LC: Labhra Cliff, SB: Southwest Bay, SI: South Island, H: Harbour

\section{Benthic predator and prey surveys}

Sampling was performed in the shallow sublittoral zone within $2 \mathrm{~h}$ of low tide at a depth of no more than $2 \mathrm{~m}$. Nine replicate $0.25 \mathrm{~m}^{2}$ quadrats were sampled at each site with the use of snorkel and mask. A criterion for placement of the quadrat was that the substrate had to consist of rock and little or no soft sediment. Quadrats were placed haphazardly, and placement was dependent on availability of liftable boulders. Muntz et al. (1965) surveyed areas of $2 \mathrm{~m}^{2}$ at 4 sites and $4 \mathrm{~m}^{2}$ at 3 sites and reported total abundances of invertebrates for the different areas surveyed. In the present paper we converted these 
abundances to number of individuals per $\mathrm{m}^{2}$. The original survey did not specify whether separate small quadrats were used and then data pooled to provide an estimate of abundance for the area surveyed, or whether an entire area was demarcated and then surveyed per site. Considering this uncertainty, we chose to measure 9 replicate $50 \mathrm{~cm} \times$ $50 \mathrm{~cm}$ quadrats each representing $0.25 \mathrm{~m}^{2}$ (and a pooled area of $2.25 \mathrm{~m}^{2}$ per site). We felt that this was sufficient to replicate the historical survey and provide contemporary estimates of abundance on a replicated per $\mathrm{m}^{2}$ basis. Furthermore, the use of 9 replicate samples using a paired Wilcoxon signed rank test is statistically robust (Sokal \& Rohlf 1995).

At each of the 7 stations described, all rocks within each quadrat were lifted onto the boat and examined. Records were made of 4 common species of potential prey, Paracentrotus lividus, Gibbula cineraria, Anomia ephippium and Chlamys varia; starfish predators Marthasterias glacialis and Asterias rubens; and the detritivore Asterina gibbosa. (The choice of prey species in the present study reflected the identity of prey recorded by Muntz et al. 1965, who simply recorded 4 common prey species). Specimens were collected and recorded separately for the tops, sides and bottoms of upper layer or lower layer boulders. Collected specimens were removed to the laboratory for weight and length measurements (to the nearest $\mathrm{mm}$ using Vernier callipers) and subsequently returned to the sample site. P. lividus was measured across the diameter; $C$. varia was measured from umbo to rim and along the width of the hinge; G. cineraria shells were measured for height and diameter; and $A$. ephippium length was measured in situ from the umbo to the tip of the shell. All starfish were measured by arm length, with the central disc to the tip of the longest arm being measured when arms were of uneven size.

\section{Algal survey}

An algal survey of the South Basin perimeter was conducted using snorkel and mask. The survey identified the extent of herbivorous grazing by sea urchins. Paracentrotus lividus can exert a strong influence on algal distribution within Lough Hyne and keep large areas, called urchin barrens, free of macroalgal growth. The perimeter of the shoreline is divided into numbered sectors (see Kitching \& Thain 1983). The survey was conducted along the South Basin shoreline as per these numbered sectors at low tide within $4 \mathrm{~m}$ of the shore. The sectors covered were South Shore, S1-S17; West Shore, W18-W26 and W34-W37; Castle Island South Shore, I11-I21 and the Eastern Shore, E11-E20. Intertidal graze patches that contained competing herbivorous species such as limpets and topshells were excluded from the study. The area of all urchin barrens in each sector was estimated and recorded. Each patch was assumed to be circular to allow a standardised calculation for the diameter of each patch. The total length of all urchin barrens per sector was established, from which the percentage of the entire shoreline dominated by urchin barrens was calculated.

\section{Statistical analyses \\ Crab CPUE}

Crab abundances were converted to a measure of catch per unit effort (CPUE) (total catch /no. of replicate pots $\times$ fishing hours). A mean CPUE with standard error was calculated for Necora puber and Carcinus maenas, and the data were grouped in 2 ways: (1) By the 12 survey sites, facilitating a comparison with the historical surveys of Muntz et al. (1965); two-sample $t$-tests were used to test the hypotheses that, in 2010, mean CPUE differed significantly from historical values obtained in 1963. (2) By the South Basin sites $(\mathrm{n}=9)$, facilitating a more detailed comparison of crab populations in the South Basin; trends in these data were analysed with linear regressions.

\section{Benthic predator and prey surveys}

All recordings made from the $0.25 \mathrm{~m}^{2}$ quadrats were converted to densities (ind. $\mathrm{m}^{-2}$ ). For this comparison, data from each site were pooled without reference to the aspect where the specimens were collected, i.e. top, sides or bottom. Due to non-normality of the data, a paired Wilcoxon signed-rank test was used to test for differences in abundance of each species per site in 1962 and 2010.

Size frequency and spatial distribution

To test whether prey species had altered population structure and habitat selection, historical sizefrequency datasets were examined. Muntz et al. (1965) provide figures to describe the size-frequency classes and spatial distributions for 3 potential prey 
invertebrates at a limited number of sampling sites, and recorded on different aspects of the boulders (top, sides and bottoms of lower and upper layer rocks). These prey were Paracentrotus lividus (Westwood North, North Wall, West Labhra), Gibbula cineraria (Westwood North, North Wall, Codium Bay and the Harbour) and Asterina ephippium (North Wall). It was necessary to extract the actual densities (ind. $\mathrm{m}^{-2}$ ) of each species from published figures (Muntz et al. 1965). Data was extracted using ImageJ software (version 1.43). Size-frequency distributions for each species per aspect per site for 1962 were then recovered. Comparable size-frequency figures were constructed from 2010 data and compared with historical data using two-sample KolmogorovSmirnov tests.

\section{Algal survey}

Data from a 1979 survey of macroalgal cover is provided by Kitching \& Thain (1983) in a map of Lough Hyne, including both the numbered sectors and the extent of algal cover per sector. Using image analysis software (ImageJ, version 1.43), the lengths of each sector were measured, and the proportion of each sector dominated by graze patches was derived. All sectors were grouped together and algal cover in 1979 and 2010 were compared using a two-sample $t$-test. All statistical analyses were performed using the $\mathrm{R}$ statistical software package ( $\mathrm{R}$ version 2.11.1).

\section{RESULTS}

\section{Crab abundance}

The mean \pm SE CPUE for all 12 sites in 1963 was $0.095 \pm 0.059$ for Carcinus maenas and $0.007 \pm 0.003$ for Necora puber. By 2010, there was an increase by an order of magnitude in the CPUE of Necora puber $(0.125 \pm 0.041, \mathrm{p}=0.016$, two-sample $t$-test, $t=0.410)$. There was also an increase in the CPUE of $C$. maenas $(0.146 \pm 0.092)$, but this increase was not significantly different from abundances reported in 1963 $(\mathrm{p}=0.642, t=0.869)$. C. maenas is generally more abundant in the North Basin (North Wall, Westwood North and West Labhra). N. puber is found in greater numbers in the South Basin (see Fig. S1 in the supplement at www.int-res.com/articles/suppl/m440 p115_supp.pdf).

The abundance of crabs in the South Basin reflects that of the main survey, but the increase in Necora puber is more apparent. CPUE for $N$. puber increased significantly ( $\mathrm{p}=0.023, t=0.353$ ) from $0.009 \pm 0.004$ in 1963 to $0.152 \pm 0.051$ in 2010. Carcinus maenas CPUE in 1963 was $0.029 \pm 0.023$ and increased to $0.049 \pm 0.022$ in $2010(p=0.526, t=0.752)$.

\section{Benthic predator and prey abundance}

Of 28 Wilcoxon signed-rank tests performed for primary consumers (4 benthic prey species at 7 sites), there was a highly significant $(\mathrm{p}<0.005)$ decrease in benthic prey abundance detected on 18 occasions (see Fig. 2). These included Gibbula cineraria at all 7 sites $(W=0)$ and Paracentrotus lividus at all sites $(W=0)$ except East Goleen, where density increased from 4 to 10.22 ind. $\mathrm{m}^{-2}(W=5, \mathrm{p}<0.01)$. This was one of only 5 comparisons where an increase in abundance was observed. The other 4 increases occurred for Anomia ephippium at Westwood North $(W=0, \mathrm{p}<0.05)$ and the Harbour $(W=9, \mathrm{p}<0.05)$ and Chlamys varia at Westwood North $(W=17, \mathrm{p}<$ 0.05 ) and Codium Bay $(W=9, \mathrm{p}>0.05)$. P. lividus was found at all sites except Codium Bay, with the largest density found at East Goleen. Gibbula cineraria was found at all sites except East Goleen in the present study but not at a density greater than 1.77 ind. $\mathrm{m}^{-2}$ (at both the North Wall and Westwood North). A. ephippium was not found at in 2010 West Labhra ( $W=0$; ns, not significant), Westwood South ( $W=0$, $\mathrm{ns})$ or East Goleen $(W=0, \mathrm{p}<0.005)$. Chlamys varia was not found at 4 sites in 2010, West Labhra ( $W=0$, $\mathrm{ns})$, Westwood South $(W=0, \mathrm{p}<0.005)$, East Goleen $(W=0, \mathrm{p}<0.005)$ and the Harbour $(W=0, \mathrm{~ns})$. No $P$. lividus were observed during the snorkeling census of the South Basin, and the abundance for the 2010 census is recorded as zero.

In 1962, the highest recorded density of the spiny starfish Marthasterias glacialis was 4.5 ind. $\mathrm{m}^{-2}$ (West Labhra and Westwood South). In the present survey, a highly significant $(p<0.005)$ increase of $M$. glacialis at 5 sites was demonstrated. Of the remaining 2 sites, there was an increase from 0 to 5.33 ind. $\mathrm{m}^{-2}$ at the North Wall $(W=0, \mathrm{p}<0.01)$ and from 5 to 13.3 ind. $\mathrm{m}^{-2}$ at Codium Bay $(W=12, \mathrm{p}<0.05)$. A density of 40.4 ind. $\mathrm{m}^{-2}$ was recorded at West Labhra and 29.33 ind. $\mathrm{m}^{-2}$ at East Goleen (Fig. 3). The cushion star, Asterina gibbosa declined significantly $(\mathrm{p}<$ $0.005)$ at 4 sites. Over the course of the study only 1 Asterias rubens was found (at North Wall) ( $W=0$, $\mathrm{ns})$. The decline was highly significant $(W=0, \mathrm{p}<$ 0.005 ) at the remaining 6 sites (see Fig. S2 in the supplement). 

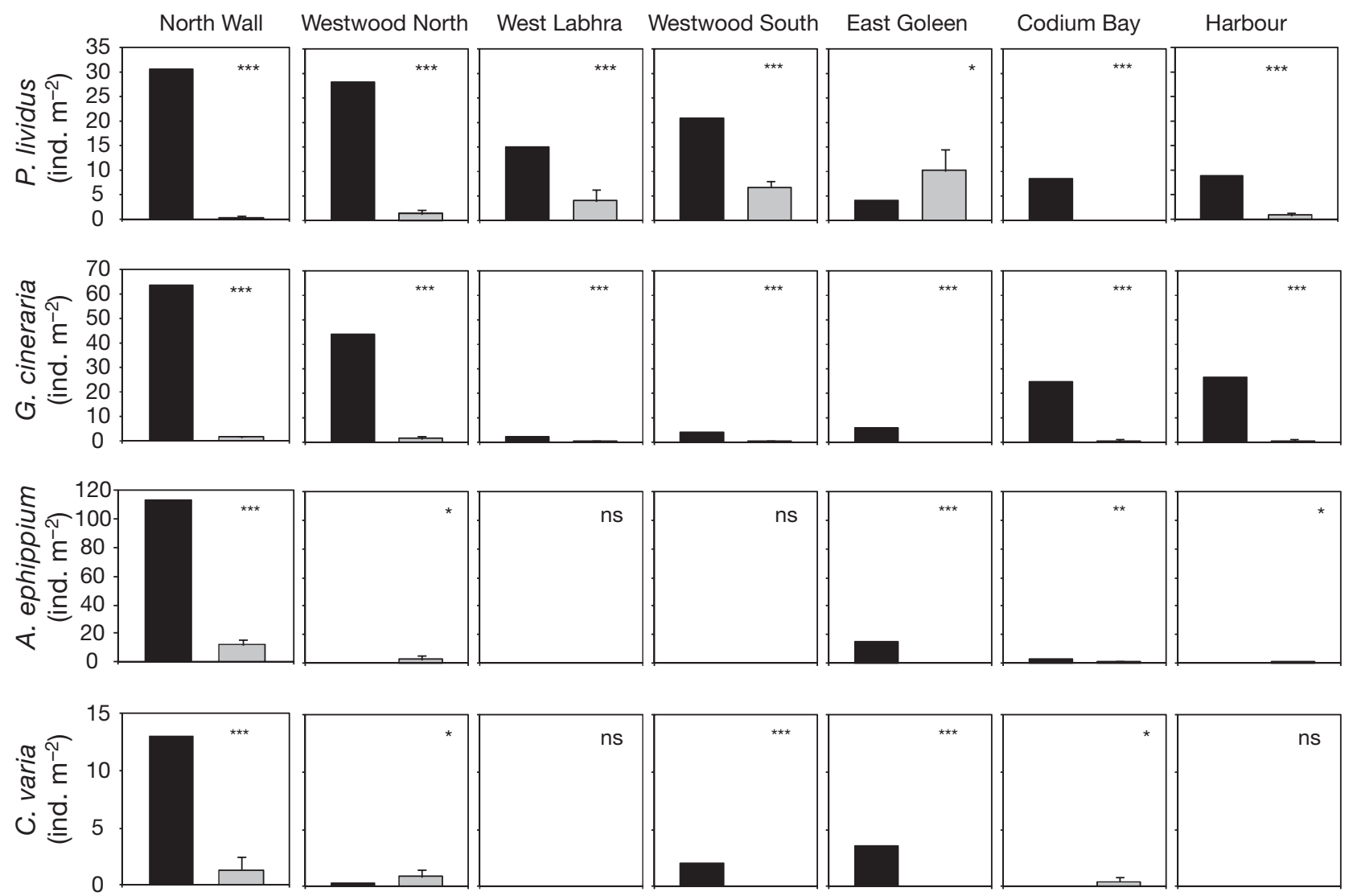

Fig. 2. Densities (ind. $\mathrm{m}^{-2}$, mean $+\mathrm{SE}$ ) of 4 common prey species (Gibbula cineraria, Paracentrotus lividus, Anomia ephippium, and Chlamys varia) recorded at 7 sites within Lough Hyne Marine Reserve in 1962 (black) and 2010 (grey). A paired Wilcoxon signed-rank test was used to test for changes in the density of each species at each site between 1962 and 2010 . Asterisks denote the degree of significance in the difference $\left({ }^{*} \mathrm{p}<0.05,{ }^{* *} \mathrm{p}<0.01,{ }^{* * *} \mathrm{p}<0.005 ; \mathrm{ns}\right.$, not significant)

\section{Size frequency and spatial distribution}

Species size distributions from the top, sides and bottoms of upper and lower layer rocks in 2010 were compared with all available historical data. Six Kolmogorov-Smirnov tests were performed per species per site. The only Paracentrotus lividus recorded at the North Wall in 2010 was on the side of a rock in the lower layer (ns). Subsequently the change in distribution of the urchins in the upper layer was highly significant at 2 aspects (top and bottom) $(p<0.005)$. At Westwood North there was a significant change in the abundance of $P$. lividus within the upper layerbottom $(\mathrm{p}<0.005)$ and the lower layer-top $(\mathrm{p}<0.01)$. At West Labhra no change in distribution was evident, except for the lower layer-top ( $p<0.05)$ (Fig. S3 in the supplement). The change in the distribution of Gibbula cineraria was most apparent at the North Wall (Fig. S4 in the supplement). The spatial distribution of Anomia ephippium in 2010 showed a signifi- cant change on the lower layer (top: $\mathrm{p}<0.01$, bottom, $\mathrm{p}<0.05$ ) and the upper layer (bottom: $\mathrm{p}<0.05$ ). Change at other aspects was not significant.

\section{Algal survey}

A total of $1794 \mathrm{~m}$ of subtidal shoreline was surveyed ( 0.5 to $1 \mathrm{~m}$ depth). Five urchin-grazed patches were recorded along the entirety of the South shore. None were larger than $0.25 \mathrm{~m}^{2}$. Graze patches were common in the very shallow intertidal but many were in association with limpets and these grazed patches were therefore not recorded. No barrens were observed on the Castle Island shore. There were 7 barrens attributed to urchins along the western shore (sectors W18-W22 from Kitching \& Thain 1983) but all were relatively small, ranging in size from 0.01 to $0.25 \mathrm{~m}^{2}$. The combined length was $2.11 \mathrm{~m}$, providing a conservative estimate of $0.91 \%$ of shoreline that 

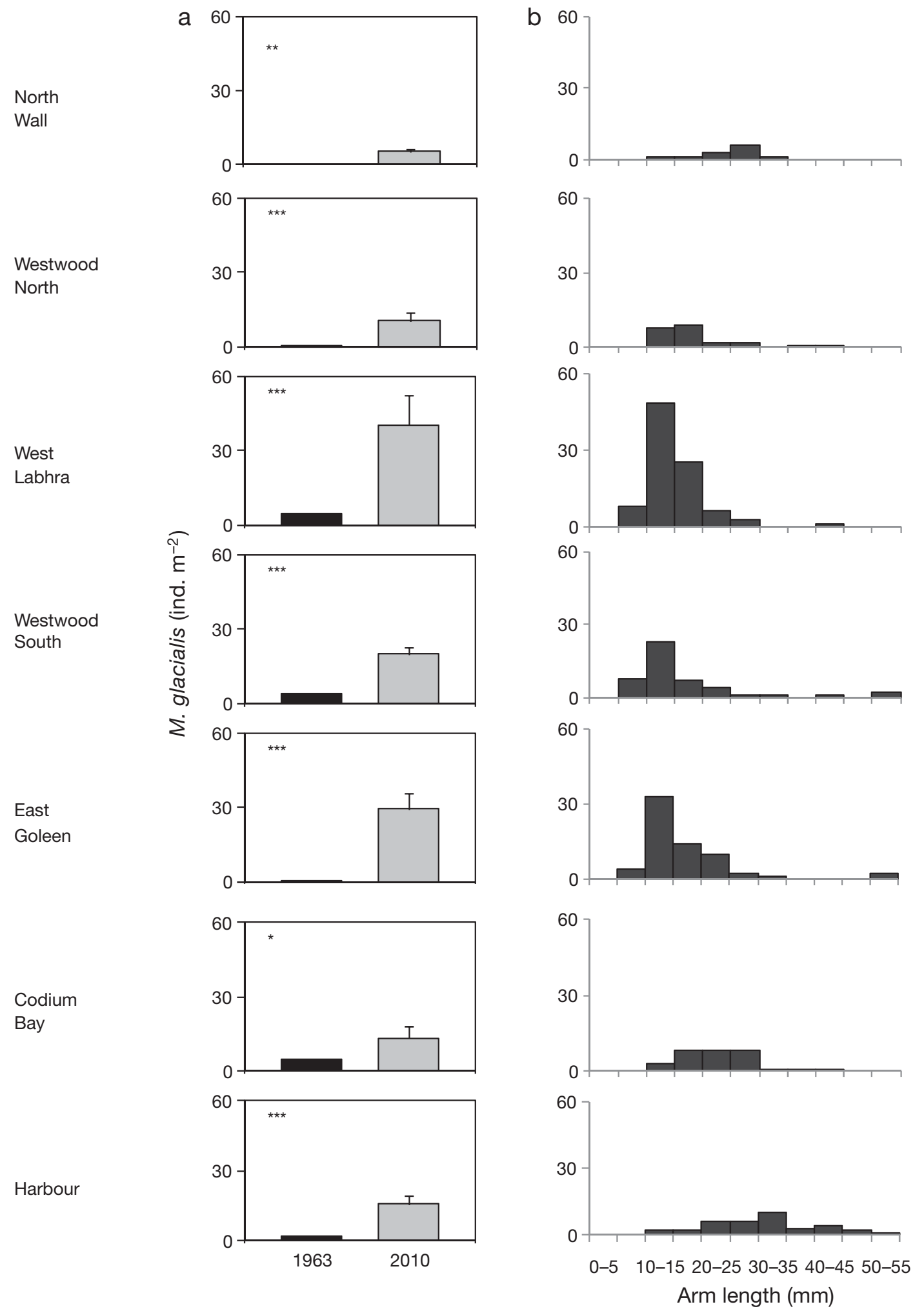

Fig. 3. Marthasterias glacialis. (a) Density (ind. $\mathrm{m}^{-2}$, mean $+\mathrm{SE}$ ) at 7 sites within Lough Hyne Marine Reserve in 1963 (black) and 2010 (grey). A paired Wilcoxon signed-rank test was used to test for changes in abundance between 1963 and 2010 . Asterisks denote the degree of significance in the difference $\left({ }^{*} p<0.05,{ }^{* *} p<0.01,{ }^{* * *} p<0.005\right)$. (b) Size frequency histograms for all sites 
was considered grazed of macroalgae in 2010. Our digital analysis of Fig. 4 in Kitching \& Thain (1983) reveals that in $197930 \%$ of the South Basin shoreline was grazed free of macroalgae. This represents a highly significant increase ( $p<0.001, t$-test) in algal coverage between 1979 and 2010. Fig. 4 highlights the change in abundance of each species occupying adjacent trophic levels and also includes the change in macroalgal cover. These patterns demonstrate how ecosystem functioning maybe affected due to increased predation with subsequent indirect effects on prey populations.

\section{DISCUSSION}

Lough Hyne was designated Europe's first Marine Nature Reserve in 1981 to protect the rich biodiversity that occurs within its depths. However, consider- ing that Lough Hyne exists as a reserve in isolation, its efficacy in conserving biodiversity is questionable. Small reserves can be more effective when they are part of a larger network that facilitates the import and export of marine species and promotes interbreeding between subpopulations (Lubchenco et al. 2003). The Single Large or Several Small (SLOSS) debate on reserve designation is fundamental to conservation theory (McCarthy et al. 2011). In the absence of dispersal, the number of reserves that minimizes the total extinction risk can be very large (thousands), and it may therefore be better to focus on implementing many small reserves to minimize the risk of extinction for any single species. Furthermore, establishing a marine reserve does not guarantee that conservation benefits will be distributed equally. Lindberg et al. (1998) suggested that marine reserves control biodiversity through indirect influences on species abundances by shaping predator

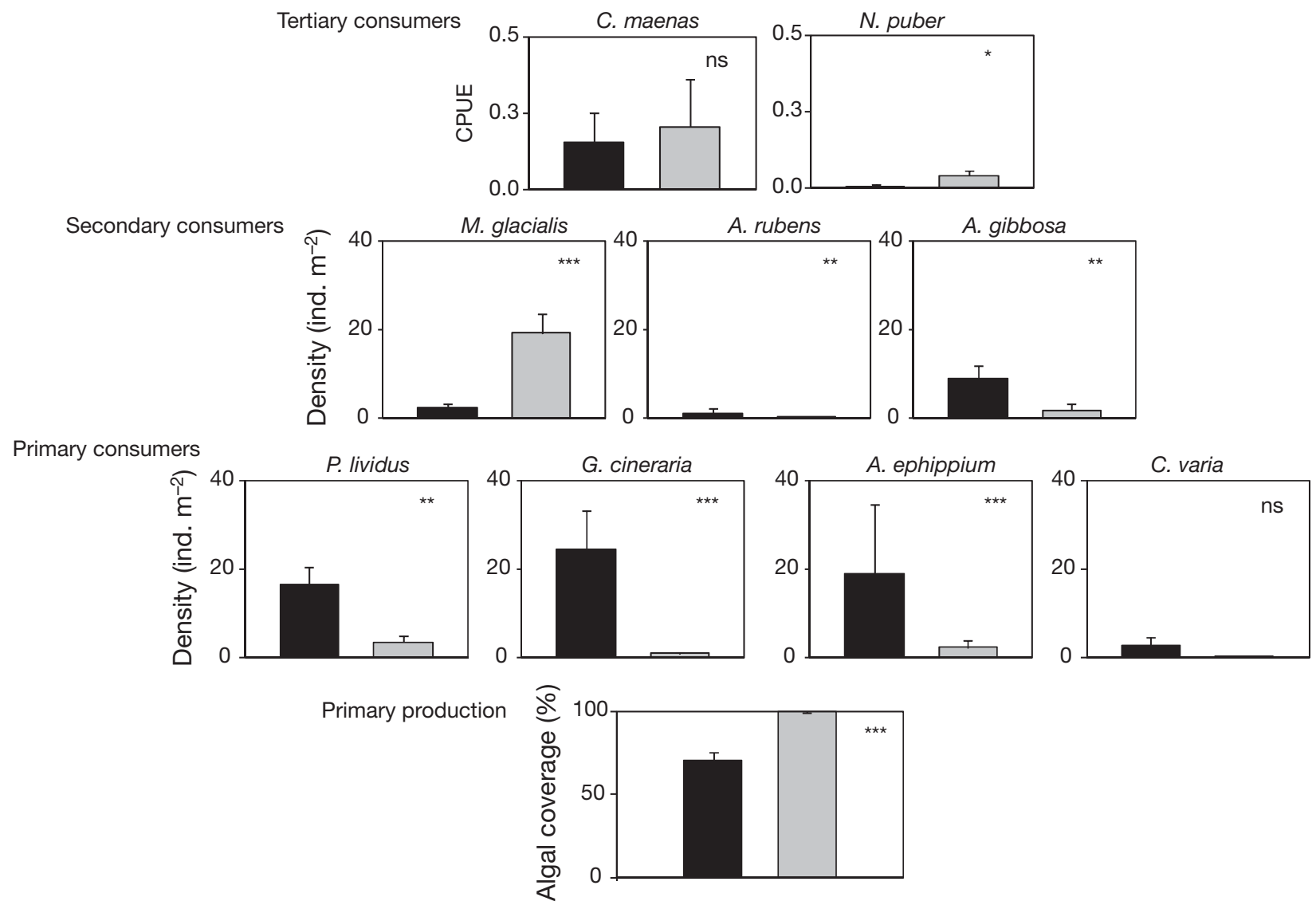

Fig. 4. Ecosystem changes at 4 trophic levels in Lough Hyne between 1963 (black) and 2010 (grey). Algal coverage has significantly increased since 1979 whilst 4 primary consumers, representing 4 different taxa, have declined in abundance. The starfish M. glacialis has significantly increased in numbers, as have the predatory crustaceans $N$. puber and C. maenas. These changes across 4 trophic levels are indicitive of a trophic cascade being forced by top-down pressure. Data are pooled from 7 sites, error bars: + SE. Asterisks denote significance of change using $t$-tests $\left({ }^{*} \mathrm{p}<0.05,{ }^{* *} \mathrm{p}<0.005,{ }^{* * *} \mathrm{p}<0.001\right.$; ns, not significant). Species Carcinus maenas and Necora puber (tertiary consumers); Marthasterias glacialis, Asterias rubens, and Asterina gibbosa (secondary consumers); Paracentrotus lividus, Gibbula cineraria, Anomia ephippium, and Chlamys varia (primary consumers) 
guilds and thus altering trophic structure. The trophic interactions in Lough Hyne are typical of any natural sublittoral system with predator-prey dynamics constantly evolving in light of fluctuating relative abundance. These natural interactions, however, are superseded by human interference, which in itself constitutes a trophic interaction.

Though not the main focus of the study, existing historical data for Paracentrotus lividus allows a detailed examination of sea urchin population dynamics and subsequent indirect effects on ecosystem functioning. The population of $P$. lividus has been in decline in Lough Hyne since 1979 (Barnes et al. 2002) and is now almost entirely absent from the upper layer of rocks, surviving at much lower densities amongst boulder scree. Whilst our results show significant declines in the abundance of this important grazer, they do not support the hypothesis that the species has become locally extinct, but that it appears to be ecologically extinct (sensu Estes et al. 1989). We propose that a series of inter-related biotic and abiotic interactions are shaping community structure.

Members of the phylum Echinodermata undergo cyclical population fluctuations (Uthicke et al. 2009). Data suggest that Paracentrotus lividus declined from counts of 18000 in 1966 to 797 in 1975 before increasing again to 15530 in 1979 (Kitching \& Thain 1983). Barnes et al. (2001) demonstrated a correlation between mass spawning events and variable sea surface temperatures (SSTs), which themselves are governed and influenced by large-scale climatic processes such as the El Niño Southern Oscillation (ENSO). However this correspondence between population size and ENSO-controlled SSTs deteriorated during the early 1980s, so it is unlikely to explain the ultimate collapse of the population (Barnes et al. 2002).

Our study demonstrates a highly significant increase in the density of the predatory crustacean $\mathrm{Ne}$ cora puber and the predatory starfish Marthasterias glacialis. A non-significant increase in the density Carcinus maenas was also observed. The timing of the onset of the most recent urchin population decline (after 1979) and of the apparent break-down in the ENSO correlation (early 1980s) coincide with the year when Lough Hyne was designated a Marine Reserve in 1981. We propose that continued low densities of the population are being mediated by an increase in direct predation from N. puber and to a lesser extent by M. glacialis. Analysis of the distribution of M. glacialis size classes reveals that juveniles are most prevalent in the shallow sub-tidal zone and may be considered too small to exert a significant influence on urchin numbers. It is possible that they inhabit the boulder scree to avoid predation from crustacean predators. The subsequent increased threat of predation has resulted in a behavioural change in P. lividus whereby it now exploits a refuge within the boulder scree around Lough Hyne. This is indicative of a trait mediated indirect interaction (TMII). The interaction between P. lividus and these 3 predators has subsequently produced an indirect effect on algal biomass and is evidence for a trophic cascade. However a number of alternative explanations may also account for the decrease in urchin numbers including: (1) direct exploitation of urchin populations within Lough Hyne over the period 1981 to 2000 ; (2) recruitment failure within Lough Hyne reflecting over-exploitation of wild sea urchin populations; and (3) the loss of genetic diversity inherent in isolated populations. Given the site's high profile status as a marine reserve it seems unlikely that overharvesting exists there, although anecdotal reports do exist. None of these explanations can be fully discounted and consequently we present the full range of hypotheses that may be responsible for altered community dynamics within Lough Hyne.

Shears \& Babcock (2003) characterised trophic cascades by top-down control of assemblages, indirect effects, and alternative community dynamics. A decrease in urchin abundance and a subsequent increase in macroalgae in response to a change in predator abundance is a well-documented marine cascade. Our results reflect those of the sea otterurchin-kelp interaction in Alaska (Duggins 1980) and are in agreement with the simple model proposed by Guidetti (2006) in which algal beds flourish in the presence of abundant predators, but with low densities of grazers. Consequently, urchins are expected to re-dominate if released from predation (Sala et al. 1998). However, without comparable data on algal coverage from 1962 (original prey survey), it is impossible to predict the effect that Paracentrotus lividus may have had at that time, and we accept the limitations that this may impose on our conclusions.

Our analysis also suggests that $<1 \%$ of the South Basin shoreline is now dominated by urchin barrens. In 1979, 30\% was considered grazed free of macroalgae. Kitching and Thain (1983) quantified the density of the limpet Patella vulgata in association with graze patches in 1979 and found them to be almost entirely absent from the South Basin at that time. Topshells, including Gibbula cineraria, are micrograzers and unlikely to have a significant impact on algal coverage. Although it is difficult to unequivocally quantify the contribution of either of these species to the grazing of patches at that time, it is likely that Para- 
centrotus lividus grazing was an important factor in regulating macroalgal coverage, and tentatively implies that the subsequent decrease in grazed patches is related to the observed decline in P. lividus abundance.

The results of the present study also indicate a system-wide decline in the abundance of 3 other common prey species in the shallow sublittoral zone in Lough Hyne - the topshell Gibbula cineraria; the saddle oyster Anomia ephippium and the scallop Chlamys varia. Such declines could be brought about by direct predation following an increase in a range of different predators. Alternatively, the decrease in grazed patches may indirectly influence these 3 common prey species. The peripheries of grazed patches are characterised by soft bushy algae (Laurencia pinnatifida, Gelidium spp.) (Kitching 1987), which offer a more favourable habitat than either crustose coralline algae, such as Lithophyllum incrustanscovered rock or larger macroalgae. These softer algae provide ideal refuge for many species and may be more palatable to prosobranch micrograzers like $G$. cineraria (Crothers 2001). Similarly, A. ephippium and C. varia have been found (historically) to be widely distributed on grazed patches (Kitching 1987), and as filter feeders may benefit from improved water circulation. There is now no discernable population structure evident in the size frequency data for Paracentrotus lividus, G. cineraria, A. ephippium and C. varia. The null hypothesis that there is no significant difference in the abundance of these species between 1962 and 2010 is rejected. However, without similar comparable datasets, it is impossible to know if the concomitant declines of G. cineraria, A. ephippium and C. varia result from both increased predation and a decline in preferential habitat or instead from similar boom/bust population dynamics. Watson \& Barnes (2004) for example, provide evidence of inter-annual fluctuations related to benthic recruitment and provide an alternative hypothesis as to the nature of these community-wide declines.

Predators such as Carcinus maenas and Necora puber were found to be the dominant crustaceans in the sublittoral zone. An order of magnitude increase in the CPUE for N. puber was found in 2010 relative to 1963, which demonstrates a significant rise in the abundance of this predator that is most apparent in the South basin. Carcinus maenas also increased in abundance, but not significantly. Muntz et al. (1965) demonstrated that $N$. puber and C. maenas are capable of preying upon the 4 benthic invertebrates surveyed here (Paracentrotus lividus, Chlamys varia,
Gibbula cineraria, Anomia ephippium), provided they were of manageable size. It is doubtful whether C. maenas and especially the larger $N$. puber feed exclusively on these species today, as the energy intake would not compensate for the metabolic expense incurred in foraging. The smaller prey items, especially A. ephippium and C. varia, are more likely to be consumed by juvenile to intermediate Marthasterias glacialis, which can in turn be fed upon by crabs. Meso-consumers, such as the starfish Asterina gibbosa, are unlikely to have an important role in the consumption of prey species in this study as it feeds primarily on decaying plant or animal material (Crump \& Emson 1983). As such, it is more prey than predator and, in the present study, has undergone a system-wide decline.

Considering the significant population declines of all 4 prey species and of Asterina gibbosa in conjunction with the increase of Marthasterias glacialis, it seems probable that the spiny starfish regulates prey abundances within the shallow sublittoral zone. It is unlikely that either large or small $M$. glacialis exert a strong direct pressure on Paracentrotus lividus. Evidence for this can be found at West Labhra, East Goleen, and Westwood South, which are the sites of highest urchin densities and highest densities of juvenile $M$. glacialis. The starfish at these 3 sites are too small to prey upon a large urchin and both species co-exist in the boulder scree, although predation of recruiting $P$. lividus by intermediate or large starfish cannot be ruled out. Juvenile M. glacialis will forage on smaller, more manageable prey items and migrate to the depths in search of more readily available, larger prey when older (Verling et al. 2003).

We suggest that the decline in Paracentrotus lividus is more indicative of a trait-mediated trophic cascade than a functional extinction. Considering that populations of all species within the benthic community now exist 'naturally', i.e. free of human exploitation, it is likely that the system has reverted to a state governed by natural dynamics, which inhibits large populations of urchins unless released from predation. Disentangling the complex interactions between trophic levels in Lough Hyne will prove difficult, but could provide information on both the species and community responses to anthropogenic effects over longer timescales. A greater understanding of behavioural traits can lead to more effective management decisions and strategies to further conserve marine biodiversity. Knowledge of ecosystem dynamics and stability under variable conditions is imperative if we are to accurately predict the consequences of forced anthropogenic pressures (Dill et al. 2003). Unfortu- 
nately, the sheer scale of human exploitation has led to 'shifting baselines', making it difficult to accurately define ecosystem change.

Thus we provide evidence for community restructuring across 4 trophic levels within Lough Hyne and further propose that the decline in the sea urchin Paracentrotus lividus and its continued suppression is directly mediated by an increase in the predators Necora puber, Marthasterias glacialis and, to a lesser degree, Carcinus maenas. This has resulted in a decrease in preferable habitat for Gibbula cineraria, Anomia ephippium and Chlamys varia, which concomitantly face increased predation pressure from the spiny starfish $M$. glacialis. This breakdown in community structure has been brought about by the designation of a marine reserve, which has resulted in altered food-web interactions and trophic cascades.

Acknowledgements. We thank D. O'Donnell of the NPWS for Lough Hyne permits and Dr. R. McAllen (UCC) for facilitating and helping to co-ordinate the fieldwork. We also thank U. Keating, S. Upton, M. McCarthy, S. Broszeit and L. Harman for field support.

\section{LITERATURE CITED}

Barnes DKA, Crook A, O'Mahoney M, Steele S, Maguire D (2001) Sea temperature variability and Paracentrotus lividus (Echinoidea) population fluctuations. J Mar Biol Assoc UK 81:359-360

Barnes DKA, Verling E, Crook A, Davidson I, O'Mahoney M (2002) Local population disappearance follows (20 yr after) cycle collapse in a pivotal ecological species. Mar Ecol Prog Ser 226:311-313

Crothers JH (2001) Common topshells: an introduction to the biology of Osilinus lineatus with notes on other species in the genus. Field Stud 10:115-160

Crump RG, Emson RH (1983) The natural history, life history and ecology of the two British species of Asterina. Field Stud 5:867-882

> Dill LM, Heithaus MR, Walters CJ (2003) Behaviourally mediated indirect interactions in marine communities and their conservtion implications. Ecology 84: 1151-1157

Duggins DO (1980) Kelp beds and sea otters: an experimental approach. Ecology 61:447-453

> Estes JA, Duggins DO, Rathbun GB (1989) The ecology of extinctions in kelp forest communities. Conserv Biol 3: 252-264

Guidetti P (2006) Marine reserves reestablish lost predatory interactions and cause community changes in rocky reefs. Ecol Appl 16:963-976

Heithaus MR, Frid A, Wirsing AJ, Worm B (2008) Predicting

Editorial responsibility: Tim McClanahan,

Mombasa, Kenya ecological consequences of marine top predator declines. Trends Ecol Evol 23:202-210

Jackson JBC (2001) What was natural in the coastal oceans? Proc Natl Acad Sci USA 98:5411-5418

Kitching JA (1987) Ecological studies at Lough Hyne. Adv Ecol Res 17:118-186

> Kitching JA, Thain VM (1983) The ecological impact of the sea urchin Paracentrotus lividus (Lamarck) in Lough Ine, Ireland. Philos Trans R Soc Lond B Biol Sci 300:513-552

> Lindberg DR, Estes JA, Warheit KI (1998) Human influences on trophic cascades along rocky shores. Ecol Appl 8: 880-890

Lubchenco J, Palumbi SR, Gaines SD, Andelman S (2003) Plugging a hole in the ocean: the emerging science of Marine Reserves. Ecol Appl 13:S3-S7

McCarthy MA, Thompson CJ, Moore AL, Possingham HP (2011) Designing nature reserves in the face of uncertainty. Ecol Lett 14:470-475

Micheli F, Halpern BS, Botsford LW, Warner RR (2004) Trajectories and correlates of community change in no-take marine reserves. Ecol Appl 14:1709-1723

> Muntz L, Ebling FJ, Kitching JA (1965) The ecology of Lough Ine XIV. Predatory activity of large crabs. J Anim Ecol 34:315-329

> Nelson EH, Matthews CE, Rosenheim JA (2004) Predators reduce prey population growth by inducing changes in prey behaviour. Ecology 85:1853-1858

> Pauly D, Christensen V, Dalsgaard J, Froese R, Torres F Jr (1998) Fishing down marine food webs. Science 279: 860-863

Sala E, Boudouresque CF, Harmelin-Vivien M (1998) Fishing, trophic cascades, and the structure of algal assemblages: evaluation of an old but untested paradigm. Oikos 82:425-439

Shears NT, Babcock RC (2003) Continuing trophic cascade effects after 25 years of no-take marine reserve protection. Mar Ecol Prog Ser 246:1-16

Sokal RR, Rohlf FJ (1995) Biometry: the principles and practice of statistics in biological research, 3rd edn. WH Freeman, New York

Thrush SF (1988) Behavioural observations on sublittoral populations of starfish in Lough Hyne. Ir Nat J 22: $430-436$

Uthicke S, Schaffelke B, Byrne M (2009) A boom-bust phylum? Ecological and evolutionary consequences of density variations in echinoderms. Ecol Monogr 79:3-24

Verling E, Crook AC, Barnes DKA, Harrison SSC (2003) Structural dynamics of a sea-star (Marthasterias glacialis) population. J Mar Biol Assoc UK 83:583-592

> Watson DI, Barnes DKA (2004) Temporal and spatial components of variability in benthic recruitment, a 5-year temperate example. Mar Biol 145:201-214

> Werner EE, Peacor SD (2003) A review of trait-mediated indirect interactions in ecological communities. Ecology 84:1083-1100

- Willis TJ, Millar RB, Babcock RC (2003) Protection of exploited fish in temperate regions: high density and biomass of snapper (Pagrus auratus) (Sparidae) in northern New Zealand marine reserves. J Appl Ecol 40:214-227

Submitted: February 11, 2011; Accepted: July 15, 2011

Proofs received from author(s): October 18, 2011 